\title{
FRACTURE RESISTANCE OF DIFFERENT ESTHETIC PARTIAL COVERAGE RESTORATIONS
}

\author{
Shaimaa Ahmed. Abo El-Farag* and Mohammed Samir El Nawawy**
}

\begin{abstract}
Statement of problem: The main factors for long-term success of indirect esthetic restorations are referred to type of restoration and preparation design.

Purpose: The aim of this in vitro study was to evaluate the fracture resistance and modes of failure of composite, ceramic and hybrid partial coverage restorations with different preparation designs.

Material and methods: A total of 42 caries-free maxillary human premolars extracted for orthodontic reasons were collected from oral surgery department, Faculty of Dentistry, Mansoura University. Teeth were divided into 3 groups $(n=14)$ according to type of restoration materials. Each group were subdivided into 2 subgroups $(n=7)$ according to preparation design; palatal coverage onlay design in which the palatal cusp was reduced by $2 \mathrm{~mm}$ and complete onlay design in which preparation included the reduction of palatal and buccal cusps. Restorations were manufactured from indirectly fabricated composite (SR Nexco), Zirconia-reinforced glass ceramic (VITA SUPRINITY) and Hybrid ceramic (VITA ENAMIC). The finished onlays were luted to prepared teeth using self-adhesive resin cement (Rely X Unicem). Specimens exposed to thermocycling 5000 cycles and then cyclic loading for 500,000 cycles. The fracture resistance of specimens were evaluated in a universal testing machine. The results were analyzed by 2-way ANOVA and Tukey HSD post hoc tests.
\end{abstract}

Results: The results of two way ANOVA test showed that there was statistically significant difference between all groups regardless of the restorative materials and preparation design. Post Hoc test showed a statistically significant difference between three restorative materials in palatal and complete coverage onlay groups $(\mathrm{P}<0.05)$. There was no statistically significant difference in the interaction between the types of restoration and preparation deign $(\mathrm{P}=0.479)(\mathrm{p}>0.05)$.

Conclusions: Zirconia-reinforced glass ceramic still the material of choice for palatal and complete onlays because of their strengthening effect on the tooth. Complete onlays showed maximum reinforcement of the tooth structure.

KEYWORDS Fracture resistance, laboratory composite, esthetic restorations, partial coverage, onlay design.

* Lecturer at Department of Fixed Prosthodontics, Faculty of Dentistry, Mansoura University, Egypt

** Lecturer at Department of Operative Dentistry, Faculty of Dentistry, Mansoura University, Egypt. 


\section{INTRODUCTION}

Indirectly fabricated partial coverage restorations such as inlay or onlay were introduced to repair carious or broken posterior teeth likewise to overcoming many of the problems associated with directly fabricated restoration such as inappropriate proximal or occlusal anatomy, inadequate wear resistance, or mechanical characteristics of directly placed restorations. ${ }^{1}$ These restorations can be fabricated from different types of materials as metallic which refused completely from the most of patients for esthetic and other colored restorative materials as ceramic or composite ${ }^{2}$.

Using of posterior direct composite resins still the prevalent line of treatment, but the problem of polymerization shrinkage may cause its fracture and microleakage, ${ }^{3}$ leading to postoperative sensitivity, marginal discoloration and recurrent caries. ${ }^{4,5}$ Indirectly fabricated composite resin inlays and onlays were introduced to overcome the previously mentioned problems. It showed advancement in their degree of polymer conversion, mechanical behavior, wear resistance, proper contouring, accuracy of marginal adaptation, and surface texture. ${ }^{6,7}$

Newly developed type of indirectly fabricated composite such as SR Nexco, which introduced by company of Ivoclar Vivadent AG (Schaan, Liechtenstein) shows perfectly features mentioned above ${ }^{8}$ Recently, there is continuous development in properties of this composite (physically and mechanically), which causes difficulty in selection among extraorally fabricated esthetic restorative materials (composites and ceramic) for rehabilitation of destructed molars and premolars. ${ }^{9,10}$

On the other hand, indirect technique may shows some problems such as; elevated cost, additional patient visits, broad and divergent cavity preparation design and insertion of temporarization at the end of patient visit. ${ }^{11}$
The interest in esthetic dental restorations such as all-ceramic has progressed, ceramic inlays, onlays, veneers, and full-coverage crowns developed and became more popular in dental field..$^{12,13}$ Dental ceramics are considered the best material to be selected for the following advantages: highly esthetics, biocompatibility to soft tissues, preferable strength of bond between restoration and prepared tooth using resin cement and resistance to masticatory forces. ${ }^{14}$

There is a difference between ceramic and composite materials in relation to chemical composition when used in different restorations such as intra and extra-coronal restorations. Ceramics composition are formed of glass, with some crystals added for material strengthening, ${ }^{15}$, ${ }^{16}$ while composites are formed of a resinous matrix and different types of filler material. ${ }^{17}$

Recently developed CAD-CAM technologies and new dental ceramic materials, showed that full contour ceramic restorations which milled without veneering, prevent ceramic chipping and reduce wear of antagonists. ${ }^{18}$ Vita Suprinity (Vita Zahnfabrik) and Celtra duo (Dentsply) are newly developed types of glass ceramic materials. The both types are the same material but produced by two different companies. In these materials, glass ceramic is enriched with zirconia (approximately $10 \%$ by weight), this composition introduced in zirconia reinforced lithium silicate ceramic (ZLS). The glass ceramic featured a special fine-grained and homogeneous structure, which was claimed by the manufacturer to provide excellent physical qualities, consistent high load capacity, long-term reliability and excellent esthetic properties. ${ }^{19}$

Few years ago, VITA ENAMIC (polymer infiltrated ceramic network) (PICN) material developed by Vita company (Vita Zahnfabrik, Bad Sackingen, Germany). It was the first hybrid dental ceramic with a dual-network structure. Where predominant ceramic network reinforced by specific 
structure called polymer network. It was found that the characteristics of this hybride ceramic are mix between the best properties of ceramic and a composite together. ${ }^{20}$

Regarding to preparation outlines for posterior partial coverage ceramic restorations, most manufacturers recommended the minimal thicknesses of ceramic ranging from 1.5-2 mm. ${ }^{21}, 22$ Increased tooth structure removal with corresponding increased ceramic thicknesses is favorable to overcome the problem of restoration fracture. ${ }^{23}$ Common theories of preservative line of treatment for posterior teeth mainly concentrated on reinforcement of the tooth and restoration by modification of preparation designing from inlay and palatal onlay to palatal and buccal (complete) onlay or preparation of the remaining tooth structure completely for full crown restoration. ${ }^{24,25}$ Many studies were performed on different designs of preparation and showed that, the tooth reduction for partial coverage crown (as onlay) in posterior area will reduce the amount of tooth removal by more than $40 \%$ in comparison to full crown preparation. ${ }^{26}$ Another important factor of the restored tooth is the applied load which stimulate failure of tooth and its restoration that can been evaluated using fracture resistance test. This indicates using of different designs and restoration materials that provide increased protection against toothrestoration failure. ${ }^{27}$ The protection of the restored tooth structure must be taken into consideration and more preferred than the selected materials used. It was found that, when the restoration is luted to prepared tooth structure, the fracture strength of this tooth is increased ${ }^{28}$ Using of bicuspids in research works provides more convenient and acceptable circumstances for partial coverage restorations than molars because of the following: preparations are mainly reduced, the force of mastication and stresses concentration at the adhesive area are minimal in strength, and more accessible for dental treatment. ${ }^{29}$
According to the aforementioned literature, there is scarce information about the fracture resistance of hybrid ceramics partial coverage restorations so, the current study was designed to estimate and compare the fracture resistance and modes of failure of composite, ceramic and hybrid restorations with different preparation designs. The null hypothesis was that different restorative materials with different preparation designs does not affect the fracture resistance of onlay restorations.

\section{MATERIALS AND METHODS}

The laboratory fabricated restorations used in the present study were: lab composite SR Nexco (SR) (IvoclarVivadent AG, Schaan, Liechtenstein), Vita Suprinity (VS); Zirconia-reinforced lithium silicate ceramic (Vita Zahnfabrik, Germany), Vita Enamic hybride dental ceramic (VE) (Enamic, Vita Zahnfabrik). All materials were used according to the manufacturer's recommendations. Self-adhesive resin cement (Rely X Unicem) used for cementation of tested restorations.

\section{Specimens selection and grouping:}

Sound forty two maxillary human bicuspids extracted from healthy persons for orthodontic causes were obtained from oral surgery department, faculty of dentistry, Mansoura University.

All teeth were cleaned from any remnants kept in $0.1 \%$ thymol disinfectant solution about 72 hours performed carefully, then were stored in distilled water at $37^{\circ} \mathrm{C} \pm 1^{\circ} \mathrm{C}$, that changed every five days during the work using an incubator (BTC, BioTech Company, Cairo, Egypt). ${ }^{11}$ Roots of selected premolars fixed in cylindrical ring $(1.4 \mathrm{x} 2 \mathrm{~cm})$ using fast setting polyester acrylic resin (Acrostone, Egypt) up to $2 \mathrm{~mm}$ below the cemento-enamel junction (CEJ). The teeth were centralized in acrylic resin using guiding device (Drill press, model No. ZJ 4110).

Totally selected teeth were divided randomly into three main divisions $(\mathrm{n}=14)$ depending on used 
type of restoration materials, then each division was subdivided into two subdivisions $(\mathrm{n}=7)$ according to preparation designs (palatal and complete onlay), finally we had 6 groups as the following:

Group I. Palatal onlay restored with SR Nexco. (PSR)

Group II. Complete onlay restored with SR Nexco. (CSR)

Group III. Palatal onlay restored with Vita Suprinity. (PVS)

Group IV. Complete onlay restored with Vita Suprinity. (CVS)

Group V.Palatal onlay restored with Vita Enamic hybride. (PVE)

Group VI. Complete onlay restored with Vita Enamic hybride. (CVE)

First preparation design of palatal onlay (PO) performed by reduction of palatal cusp by $2 \mathrm{~mm}$ while second design of complete onlay (CO) included the preparation of both palatal and buccal cusps by $2 \mathrm{~mm}$.

Standardized onlay cavities preparation was made using a high-speed handpiece (Sirona T3, Bensheim, Germany) fixed in a specially designed device at Production Engineering and Mechanical Design Department, Faculty of Engineering, Mansoura University. This device produced preparation with standard dimensions. ${ }^{11}$ The first design (PO) were prepared with the following dimensions; 2.5 $\mathrm{mm}$ depth of pulpal floor was measured from the occlusal surface, $2.5 \mathrm{~mm}$ of occlusal isthmus width, and widths of mesial and distal boxes buccolingually were $2.5 \mathrm{~mm}$. Depth of gingival floor was $1.5 \mathrm{~mm}$ for each box and the axial wall height was $2 \mathrm{~mm}$, the reduction of palatal cusp $2 \mathrm{~mm}$ according to the morphological anatomy of the occlusal surface, finally, $1 \mathrm{~mm}$ rounded shoulder of finished palatal margin. The second design (CO) were prepared with the same previously mentioned dimensions in addition to reduction of buccal cusp by $2 \mathrm{~mm} .{ }^{11}$
Fabrication of the indirect restorations: (SR Nexco lab composite resin)

Impression of prepared teeth was performed using impression material such as a vinylpolylsiloxane (Express XT, 3M ESPE, St. Paul, Minnesota) with double mixing technique. Pouring of the resulted copies using Type IV gypsum material (Elite rock, Zhermack SpA, Badia Polesine, Italy). All restorations fabricated by the same technician on the die model according to the manufacturers' recommendations. ${ }^{11}$

Any undercuts in preparation were closed using wax for easy removal of the polymerized restoration without destroying the die model, then margins of the die were demarcated with red pencil. Two thin layers of SR Separator (Ivoclar Vivadent AG) was painted. A thick coat of liner of the same company was inserted into the walls and floor of preparation, each part was hardened using light cure (LED) for $20 \mathrm{sec}$ (Ledition, Ivoclar Vivadent AG). The restoration applied by layering technique (Dentin and Incisal) and each layer was cured for $20 \mathrm{sec}$, after that, finally applied restoration was cured from each direction for additional $20 \mathrm{sec}$., and then the polymerization of the material was completed by inserting the restorations into the oven (Targis Power TP3 Upgrade, Ivoclar Vivadent AG) for 11 minutes according to manufacturer instructions, after that each restoration was eliminated from its corresponding die then finished and polished. The inner walls of onlays was treated by sandblasting with $80 \mu \mathrm{m}-100 \mu \mathrm{m} \mathrm{Al}_{2} \mathrm{O}_{3}$ at 1 bar pressure to increase the bond strength with the luting cement. ${ }^{11}$

\section{Fabrication of Vita-suprinity and Vita-enamic restorations}

Fabrication of The CAD/CAM ceramic onlay restorations were made from the following materials: lithium silicate reinforced ceramics enriched with $\mathrm{ZrO} 2$ (Vita Suprinity) and glass ceramic in a resin interpenetrating matrix (Vita Enamic). Design 
was made as STereoLithography "STL file" to be accepted in all open system CAD/CAM machines. This "STL file" was transferred to the CAD software (Ceramill mind software, Amann Girrbach, Austria) and the virtual design was presented on its screen. STL-files of the restorations were sent to a dental milling center where they were milled according to the standard manufacturer's procedures. Selection of ceramic material name was done from the software liberary in the milling file and entered all details about the block and the used shade was A3 HT (high translucency). Steps of fixation of the blocks, milling of the onlay restoration, separation of the milled restorations and finishing were performed regarding to the manufacturer recommendations. ${ }^{30}$

\section{Cementation of the restorations}

Try-in was done for all restorations then bonding was performed according to manufacturer instructions using Rely X Unicem. Teeth surfaces were treated by $37 \%$ phosphoric acid etching agent followed by water rinsing till obtain a slightly glossy wet appearance of dentin surface. Teeth were painted with Syntac primer (Ivoclar Vivadent AG) for $15 \mathrm{sec}$. then dried using air, after that Syntac adhesive was applied for $10 \mathrm{sec}$. and dried again with air. Slender coat of bonding agent (Heliobond, Ivoclar Vivadent, Inc) was used but without curing (polymerized with Rely X Unicem after insertion of restoration). Dual-polymerizing, self-adhesive resin cement (Rely X Unicem, 3M ESPE) painted to fitting surfaces of onlays, then cemented to the prepared teeth. After setting of cement, excess was removed all around the margins. ${ }^{11}$

\section{Testing procedure}

All cemented specimens were preserved in a distilled water at $37^{\circ} \mathrm{C}$ for 24 hours till beginning of test. For simulation of intraoral conditions, they were subjected to thermocycling (Theromocycler, Robota, Alexandria, Egypt, found in the department of Dental Biomaterial at Faculty of Dentistry,
Mansoura University) for a total number of 5000 cycles between $5^{\circ} \mathrm{C}$ and $55^{\circ} \mathrm{C}$ with a dwell time 30 $\mathrm{sec}$, after that all specimens were fixed on the other machine for cyclic loading (found in the department of Production Engineering at Faculty of Engineering, Mansoura University) which filled with distilled water at $37^{\circ} \mathrm{C}$ as temperature of oral cavity. The loading cycles were done for 500000 cycles with an 8-mm diameter metal sphere, the applied load with a peak of $100 \mathrm{~N}$ directed within long axis of specimens with a frequency of 75 cycles/minute. ${ }^{31}$ The universal testing machine (Instron Universal testing machine, model no. 3345, England) was used for compressive loading application using of a metal sphere ( $8 \mathrm{~mm}$ diameter) applied in vertical direction to be in the intimate contact with the slopes of cusp at a crosshead speed of $0.5 \mathrm{~mm} / \mathrm{min}$. Force required for specimen fracture was measured in Newton (N). Specimen's modes of failure were categorized as follows: fracture of the tooth itself called cohesive (CS), failure between the tooth and restoration called adhesive (AD), fracture of the restoration only called cohesive failure within the material $(\mathrm{CM})$, and fracture of the restoration and tooth completely called complete failure $(\mathrm{CO}){ }^{27}$

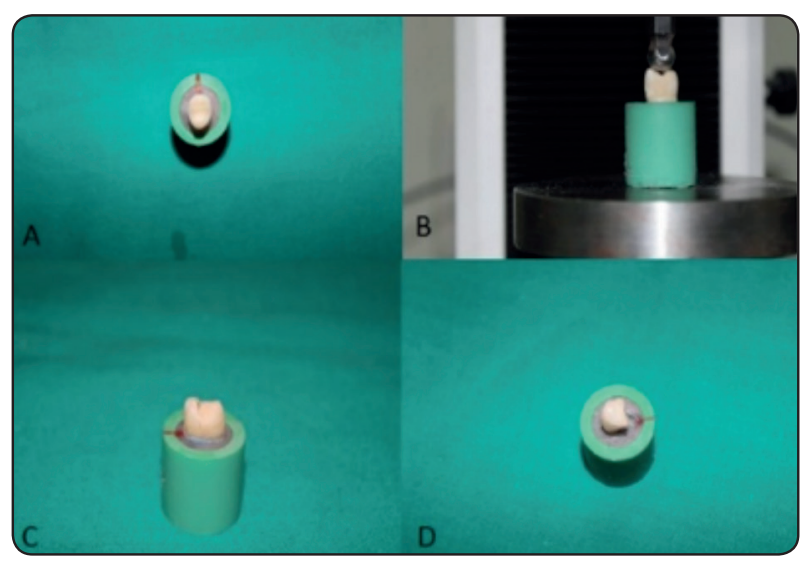

Figure 1 showing: A: onlay preparation design, B: compressive loading application. C: complete fracture of the specimen. D: fracture and separation of restoration from tooth. 


\section{Statistical analysis}

Significance of difference between groups variability was tested using two-way ANOVA parametric test followed by Post-hoc Tukey tests for comparing data between each group.

\section{RESULTS}

Mean and standard deviations (SDs) of fracture resistance values were showed in (Table 1). The outcomes of two way ANOVA test displayed that there was statistically significant difference among all groups regardless of restorative materials and preparation designs. Post Hoc test exhibited a statistically significant difference between the three restorative materials in both preparation designs ( $\mathrm{P}$ \& C) $(\mathrm{P}<0.05)$. Regarding to fracture resistance of used materials, the results of the current study showed that, the highest values were recorded for Vita Suprinity ceramic in both designs (1389.6, 1530 $\mathrm{N}$ respectively) followed by Vita Enamic (1100.7, $1182.1 \mathrm{~N}$ respectively) and the lowest values were for SR Nexco composite (861, $971.5 \mathrm{~N}$ respectively) but there was no statistically significant difference in the interaction between the type of restorations and preparation deigns $(\mathrm{P}=0.479)(\mathrm{P}>0.05)$. It was found that the highest mean fracture resistance value was reported for CVS group (1530 N), while the lowest mean value was observed for PSR group $(861 \mathrm{~N})$. The patterns of fracture for all specimens with palatal and complete onlay designs were recorded in (Table 2).

TABLE (1) Showing: Mean and stander deviation (SDs) of fracture resistance values in Newton (N) for all tested groups.

\begin{tabular}{|c|c|c|c|c|c|c|c|c|}
\hline & $\begin{array}{c}\text { Palatal } \\
(\text { Mean } \pm \text { SD) }\end{array}$ & $\begin{array}{c}\text { Complete } \\
(\text { Mean } \pm \text { SD) }\end{array}$ & P1 & $\mathrm{P} 2$ & P3 & $\mathrm{P} 4$ & P5 & P6 \\
\hline Resin & $860.91 \pm 46.91$ & $971.50 \pm 85.72$ & \multirow[t]{3}{*}{0.000} & \multirow{3}{*}{0.000} & \multirow[b]{3}{*}{0.000} & \multirow[t]{3}{*}{0.000} & \multirow[t]{3}{*}{0.000} & \multirow[t]{3}{*}{0.479} \\
\hline Ceramic & $1389.62 \pm 93.97$ & $1530.07 \pm 93.97$ & & & & & & \\
\hline Hybrid & $1100.78 \pm 49.84$ & $1182.14 \pm 73.66$ & & & & & & \\
\hline
\end{tabular}

P1: P value between palatal and complete onlay design in SR Nexco restoration group

P2: P value between palatal and complete onlay design in VS restoration group

P3: P value between palatal and complete onlay design in VE restoration group

P4: P value between the three restorations in in palatal onlay design.

P5: P value between the three restorations in complete onlay design.

P6: $P$ value of the interaction between the all restorations and the preparation designs. 
TABLE (2) showing: Fracture patterns of tested groups

\begin{tabular}{|l|l|l|l|l|}
\hline Groups & CS & AD & CM & CO \\
\hline Palatal Resin & 1 & 2 & 1 & 3 \\
\hline Palatal Ceramic & 1 & 1 & 0 & 5 \\
\hline Palatal Hybrid & 1 & 2 & 0 & 4 \\
\hline Total & $\mathbf{3}$ & $\mathbf{5}$ & $\mathbf{1}$ & $\mathbf{1 2}$ \\
\hline Complete Resin & 0 & 0 & 2 & 5 \\
\hline Complete Ceramic & 0 & 0 & 0 & 7 \\
\hline Complete Hybrid & 0 & 0 & 1 & 6 \\
\hline Total & $\mathbf{0}$ & $\mathbf{0}$ & $\mathbf{3}$ & $\mathbf{1 8}$ \\
\hline
\end{tabular}

$(C S)$ : cohesive fracture of the tooth itself, $(A D)$ : adhesive fracture between the tooth and restoration, (CM): cohesive fracture of the restoration only, and $(\mathrm{CO})$ : complete fracture of the restoration and tooth.

\section{DISCUSSION}

Null hypothesis of this study was rejected since the different restorative materials with different preparation designs affected the fracture resistance of onlay restorations. Selected type of tooth (bicuspid or molar) may provide the great effect on the implementation of composite and ceramic restorations. ${ }^{32}$ Vitality of the teeth also affects the clinical performance of both esthetic materials; previous research works provided that using of composites in restoration of non-vital teeth was preferred than ceramics. ${ }^{33,34}$ Finally, the dentist is the only person who responsible for taking decision to select between different materials and designs according to the acceptable and accurate line of treatment.

In this in-vitro study bicuspids are the most suitable type of teeth to be used because these teeth have been proved to show a high fracture rate in the clinical status. Many studies showed that the buccal cusps of upper premolars liable for fracture more than palatal cusps, they concluded that, nonfunctional buccal cusp displayed high percentage of fractures up to $60 \%$ while the remaining $40 \%$ was observed on the functional palatal cusp. ${ }^{35}$ In the present study, different materials were used for fabrication of onlay restorations such as allceramic materials that provided an excellent choice for esthetic restorations. ${ }^{36}$ On the other side, indirect laboratory composite was used to overcomes the main problem for direct composite resin which is polymerization shrinkage ${ }^{37}$ All specimens were luted using Dual-polymerizing, self-adhesive resin cement (Rely X Unicem, 3M ESPE) as it is the available, simple and applicable type for permanent adhesion. ${ }^{11}$ Finally, all luted restorations were applied in a thermocycling machine and exposed to 5000 thermal cycles to mimic intraoral environmental conditions by exposure to different temperature degrees, after that specimens submitted to 500000 cycles in the cyclic loading device to be under conditions similar to the masticatory forces at posterior area intraorally. ${ }^{11}$

Lab composite specimens demonstrated lower values of fracture resistance than the other two groups. This referred to the modulus of elasticity of the indirect composite which is less than that of restored tooth. ${ }^{38}$ Consequently, using of SR composite restorations caused stress concentration at the tooth structure during vertical compressive pressure, resulting in reduced values of fracture resistance. ${ }^{39,40}$ This outcome was corresponding to 
research of Wafaie et al. ${ }^{11}$ who concluded that the restoration of teeth using ceramic material showed more fracture resistance than laboratory composite restorations. Zirconia ceramic group (Vita Suprinity) demonstrated greater resistance for fracture than the other two groups (Vita Enamic and SR Nexco composite) and this rational result was due to elevated flexural strength and fracture toughness of partially stabilized zirconia-based ceramic that referred to its transformation toughening. This physical property is very important as it is the main cause for the transition of yttria partially stablized zirconia polycrystalline from a tetragonal crystalline to monoclinic phase under stress that inhibits and prevents the prevalence of crack and stress corrosion. ${ }^{41} \mathrm{CAD} / \mathrm{CAM}$ technology was preferred as it can produces permanent restoration in a single session with minimal internal flaws and avoiding cracks, in comparison to other conventional ceramic restorations. ${ }^{11}$ This result was in agreement with the research work of Ma et al.$^{42}$ who explained that zirconia showed greater fracture load (2.5 times) than other types of ceramic so, this material is more favorable to be applied in posterior regions of oral cavity. The resistance to fracture of both VS and VE groups was more than that of SR group. This may be referred to variation in the modulus of elasticity between all used materials as, VS explained the highest elastic modulus then VE finally SR composite. Therewith, this result conflicted with Brunton et al., ${ }^{9}$ who concluded that higher resistant to fracture was observed for lab composite than ceramic.

They explained that the lab composite characterized by greater flexibility and low rigidity which allow the deflection of the restored tooth under applied occlusal forces. Many research works showed that there are many factors may affect the fracture resistance of dental ceramic restoration such as microstructure, fatigue of the ceramic material, technique of its fabrication, different designs of tooth preparation and cementation procedure. Slight surpass of Suprinity in the fracture resistance, could be related to its composition of zirconia fillers which increase its fracture strength. On the other hand, the approximate values of fracture resistance showed by Enamic, could be due to the presence of polymer in its composition which reduces the brittle fracture and lead to increase fracture resistance..$^{43} \mathrm{In}$ the current study two preparation designs including palatal and complete onlay preparations were used. These designs are commonly advised for providing more support and strengthen the weakened tooth structure against fracture. ${ }^{25}$

The onlay preparation design characterized by incomplete tooth reduction, ${ }^{26}$ leading to acceptable stresses distribution in prepared tooth and decreased liability for fracture. The results of the present research work showed statistically significant difference of the fracture resistance between the two preparations deigns regardless of the used restorative materials. The first preparation design (PO) showed reduced values than the second design $(\mathrm{CO})$. These findings were disagreement with research work of Kantardzic I et al., ${ }^{44}$ who found that, the reduction of palatal cusp only provided ideal stress distribution than inlay and preparation of both palatal and buccal cusps (CO). Other research work performed by Cubas GB et al., ${ }^{45}$ concluded that palatal and complete onlay preparations have no influence on promoting the fracture resistance of restored bicuspids. On the other hand the outcomes of current work was in agreement with the Harsha et al., ${ }^{18}$ who found that although the inlay and palatal onlay preparation designs reinforced the prepared tooth structure, complete onlays showed the greatest reinforcement of the tooth. Beside the fracture resistance test, analysis of failure modes was important to be evaluated to explain the failure prospection of each specimen in different clinical situations. Mode of failure of Vita suprinity (glass ceramic) in both onlay designs showed totally fractured specimen more than Hybride ceramic. Vita Enamic is characterized by the presence of polymer 
part which is formed from urethane dimethacrylate (UDMA) and triethylene glycol dimethacrylate (TEGDMA) ${ }^{46,}, 47$ This network of the polymer in the material structure allows more absorption of masticatory forces than glass ceramics. ${ }^{46,48}$ It also increases the material resistance to crack initiation and growth by their effect on material elasticity and hardness. ${ }^{48,} 49$ Also the presence of porosity of PICN material increased, its flexural strength increased and its modulus and hardness decreased. ${ }^{\mathbf{5 0}}$ Clinical fractures of VITA Enamic material might occur as a result of low modulus of elasticity and inert biaxial flexural strength of the material when compared to other types of ceramic systems. ${ }^{51}$, ${ }^{52}$ Indirect lab composite palatal onlay showed adhesive fracture at the interface while complete onlay showed complete specimen fracture. These modes of failure can be explained as, the stresses created from cyclic loading was absorbed by adhesively luted SR composite, then transferred it to the restored tooth. Subsequently, both tooth and restorative material continued to concentrate the stress until it fractured. This result agreed with Fonseca et al. ${ }^{53}$ who concluded that mainly occurred failure included both indirect composite restoration and prepared tooth.

\section{CONCLUSION}

Within the conditions of the present study, the following conclusions can be drawn:

Lithium silicate zirconia ceramic can be selected as the preferable restorative material to palatal and complete onlay designs because of its reinforcing effect on the tooth structure.

Complete onlays showed maximum reinforcement of the tooth than palatal design regardless of used material.

All premolars restored with lithium-silicate ceramic (Vita suprinity) palatal coverage restorations showed failure loads overtopping physiologic mastication forces.

\section{REFERENCES}

1. Barone A, Derchi G, Rossi A, et al. Longitudinal clinical evaluation of bonded composite inlays: a 3-year study. Quintessence Int. 2008;39:65-71

2. McGill S, Holmes J: The $7 / 8$ crown: a lost art. Oper Dent 2012; 37:453-457.

3. Giachetti L, Scaminaci RD, Bambi C, Grandini R. A review of polymerization shrinkage stress: current techniques for posterior direct resin restorations. J Contemp Dent Pract. 2006; 7:79-88.

4. Ferracane JL. Resin composite-state of the art. Dent Mater. $2011 ; 27: 29-38$.

5. Manhart J, Kunzelmann KH, Chen HY, et al. Mechanical properties and wear behavior of light-cured packable composite resins. Dent Mater. 2000; 16:33-40.

6. Chang HS, Kim JW. Early hardness and shear bond strength of dual-cure resin cement light cured through resin overlays with different dentin-layer thicknesses. Oper Dent. 2014; 39:398-406.

7. Fron CH, Smail FV, Attal JP. Clinical efficacy of composite versus ceramic inlays and onlays: a systematic review. Dent Mater. 2013; 29:1209-1218.

8. Todd JC. Scientific Documentation SR Nexco Paste, Liechtenstein: Ivoclar Vivadent AG, Research and Development Scientific Service, 2012.

9. Brunton PA, Cattell P, Burke FJT, et al. Fracture resistance of teeth restored with onlays of three contemporary tooth colored resin bonded restorative materials. J Prosthet Dent. 1999; 82:167-171.

10. Thordrup M, Isidor F, Horsted-Bindslev P. A 5-year study of indirect and direct resin composite and ceramic inlays. Quintessence Int. 2001; 32:199-205.

11. Wafaie RA, Ali AI, Mahmoud SH. Fracture resistance of prepared premolars restored with bonded new lab composite and all-ceramic inlay/onlay restorations: Laboratory study. J Esthet Restor Dent. 2018; 1-11.

12. Christensen JC. Porcelain-fused-to-metal vs. nonmetal crowns. J AmDent Assoc. 1999; 130:409-411.

13. Seiber C. In the light of nature. Quintessence Dent Technol. 1993; 16: 60-68.

14. Reich SM, Wichmann M, Rinne H, et al: Clinical performance of large, all-ceramic CAD/CAM-generated restorations after three years. J Am Dent Assoc 2004; 135:605-612. 
15. Chen X, Chadwick TC, Wilson RM, Hill RG, Cattell MJ: Crystallization and flexural strength optimization of finegrained leucite glass-ceramics for dentistry. Dent Mater 2011, 27:1153-1161.

16. Lin WS, Ercoli C, Feng C, Morton D: The effect of core material, veneering porcelain, and fabrication technique on the biaxial flexural strength and weibull analysis of selected dental ceramics. J Prosthodont 2012, 21:353-362.

17. Drummond JL: Degradation, fatigue, and failure of resin dental composite materials. J Dent Res 2008, 87:710-719.

18. Harsha MS, Praffulla M, Babu MR, Leneena G, Krishna TS, Divya G. The Effect of Cavity Design on Fracture Resistance and Failure Pattern in Monolithic Zirconia Partial Coverage Restorations - An In vitro Study. J Clin Diag Res. 2017; 11:45-48.

19. Sannino G, Germano F, Arcuri L, Bigelli E, Arcuri C, Barlattani A. CEREC CAD/CAM Chairside System. Oral Implantol (Rome). 2015; 7:57-70.

20. Spitznagel FA, Horvath SD, Guess PC, Blatz MB. Resin bond to indirect composite and new ceramic/polymer materials: a review of the literature. J Esthet Restor Dent. 2014; 26:382-393.

21. Ahlers MO, Morig G, Blunck U, Hajto J, Probster L, Frankenberger R. Guidelines for the preparation of CAD/CAM ceramic inlays and partial crowns. Int J Comput Dent. 2009; 12:309-325.

22. Tsitrou EA, van Noort R. Minimal preparation designs for single posterior indirect prostheses with the use of the Cerec system. Int J Comput Dent. 2008; 11:227-240.

23. Murgueitio R, Bernal G. Three-Year Clinical Follow-Up of Posterior Teeth Restored with Leucite-Reinforced IPS Empress Onlays and Partial Veneer Crowns. J Prosthodont. 2012; 21:340-345.

24. Dejak B, Mlotkowski A, Romanowicz M. Strength estimation of different designs of ceramic inlays and onlays in molars based on the Tsai-Wu failure criterion. J Prosthet Dent. 2007; 98:89-100.

25. Kuijs RH, Fennis WM, Kreulen CM, Roeters FJ, Verdonschot N, Creugers NH. A comparison of fatigue resistance of three materials for cusp-replacing adhesive restorations. J Dent. 2006; 34:19-25.

26. Edelhoff D, Sorensen JA. Tooth structure removal associated with various preparation designs for posterior teeth. Int J Periodontics Restorative Dent. 2002; 22:241-250.
27. Taha DG, Abdel-Samad AA, Mahmoud SH. Fracture resistance of maxillary premolars with class II MOD cavities restored with ormocer, nanofilled and nanoceramic composite restorative systems. Quintessence Int. 2011; 42:579-587.

28. Ohlmann B, Gruber R, Eickemeyer G, et al: Optimizing preparation design for metal-free composite resin crowns. J Prosthet Dent 2008; 100:211-219

29. Manhart J, Scheibenbogen-Fuchsbrunner A, Chen HY, Hickel R: A 2-year clinical study of composite and ceramic inlays. Clin Oral Investig 2000, 4:192-198.

30. Naumova EA, Schneider S, Arnold WH, Piwowarczyk A. Wear Behavior of Ceramic CAD/CAM Crowns and Natural Antagonists. J Mater 2017; 10, 244:1-13.

31. Saridag S, Sevimay M, Pekkan G. Fracture resistance of teeth restored with all-ceramic inlays and onlays: an in vitro study. Oper Dent. 2013; 38:626-634.

32. Manhart J, Chen HY, Neuerer P, Scheibenbogen-Fuchsbrunner A, Hickel R: Three-year clinical evaluation of composite and ceramic inlays. Am J Dent 2001, 14:95-99.

33. Magne P, Knezevic A: Simulated fatigue resistance of composite resin versus porcelain $\mathrm{CAD} / \mathrm{CAM}$ overlay restorations on endodontically treated molars. Quintessence Int 2009, 40:125-133.

34. Magne P, Knezevic A: Influence of overlay restorative materials and load cusps on the fatigue resistance of endodontically treated molars. Quintessence Int 2009, 40:729-737.

35. Bitter K, Meyer LH, Fotiadis N, Blunck U, Neumann K, Kielbassa AM, et al. Influence of endodontic treatment, post insertion, and ceramic restoration on the fracture resistance of maxillary premolars. Int Endod J. 2010; 43:469-477.

36. Montenegro AC, do Couto CF, Ventura PR, et al. In vitro comparative analysis of resistance to compression of laboratory resin composites and a ceramic system. Indian J Dent Res. 2010; 21:68-71.

37. Coelho-De-Souza FH, Camacho GB, Demarco FF, Powers JM. Fracture resistance and gap formation of MOD restorations: influence of restorative technique, bevel preparation and water storage. Oper Dent. 2008; 33:37-43.

38. Costa A, Xavier T, Noritomi P. The influence of elastic modulus of inlay materials on stress distribution and fracture of premolars. Oper Dent. 2014; 39:160-170. 
39. Kois DE, Isvilanonda V, Chaiyabutr Y, Kois JC. Evaluation of fracture resistance and failure risks of posterior partial coverage restorations. J Esthet Restor Dent. 2013; 25:110-122.

40. Magne P, Belser UC. Porcelain versus composite inlays/ onlays: effects of mechanical loads on stress distribution, adhesion, and crown flexure. Int J Periodont Restor Dent. 2003; 23:543- 555 .

41. Hopp CD, Land MF. Considerations for ceramic inlays in posterior teeth: a review. Clin Cosmet Investig Dent. 2013; $18: 21-32$.

42. Ma L, Guess PC, Zhang Y. Load-bearing properties of minimal invasive monolithic lithium disilicate and zirconia occlusal onlays: finite element and theoretical analyses. Dent Mater. 2013; 29: 742-751.

43. Johnson AC, Versluis A, Tantbirojn D, Ahuja S. Fracture strength of CAD/CAM composite and composite-ceramic occlusal veneers. J Prosthodont Res. 2014; 58:107-121.

44. Kantardzic I, Vasiljevic D, Blazic L, Luzanin O. Influence of cavity design preparation on stress values in maxillary premolars: A finite element analysis. Croat Med J. 2012; 53:568-576.

45. Cubas GB, Habekost L, Camacho GB, Pereira-Cenci T. Fracture resistance of premolars restored with inlay and onlay ceramic restorations and luted with different agents. J Prosthodont Res. 2011; 55:53-59.

46. Sonmez N, Gultekin P, Turp V, Akgungor G, Sen D \& Mijiritsky E. Evaluation of five CAD/CAM materials by microstructural characterization and mechanical tests: a comparative in vitro study. BMC Oral Health. 2018; 18:1-13.
47. Lauvahutanon S, Takahashi H, Shiozawa M, Iwasaki N, Asakawa Y, Oki M, et al. Mechanical properties of composite resin blocks for CAD/CAM. Dent Mater J. 2014; 33:705-715.

48. Spitznagel F A, Scholz K J, Strub J R, Vach K, Gierthmuehlen P C. Polymer-infiltrated ceramic CAD/CAM inlays and partial coverage restorations: 3-year results of a prospective clinical study over 5 years, Clin Oral Investig. 2018; 22:1973-1983.

49. Swain MV, Coldea A, Bilkhair A, Guess PC. Interpenetrating network ceramic-resin composite dental restorative materials. Dent Mater. 2016; 32:34-42.

50. Lawson NC, Bansal R, Burgess JO. Wear, strength, modulus and hardness of CAD/CAM restorative materials. Dent Mater.2016; 32: 275-283.

51. Silva P, Martinelli-Lobo C.M, Bottino M A, de Melo R M,\& VALANDRO L.F. Bond strength between a polymerinfiltrated ceramic network and a composite for repair: effect of several ceramic surface treatments, Braz. Oral Res. 2018;32:1-9.

52. Ramos NC, Campos TM, Paz IS, Machado JP, Bottino MA, Cesar PF et al. Microstructure characterization and SCG of newly engineered dental ceramics. Dent Mater. 2016; 32:870-878.

53. Fonseca RB, Fernandes-Neto AJ, Correr-Sobrinho L, Soares CJ. The influence of cavity preparation design on fracture strength and mode of fracture of laboratory-processed composite resin restorations. J Prosthet Dent. 2007; 98:277-284. 